\title{
O conhecimento local sobre a fauna edáfica e suas relações com o solo em agroecossistema familiar de base ecológica: um estudo de caso
}

\author{
Local knowledge on soil fauna and its soil relationship in an agroecological \\ family farm: a case study
}

\begin{abstract}
Greice de Almeida Schiavon ${ }^{\text {I }}$ Ana Cláudia Rodrigues de Lima ${ }^{\text {II }}$ Gustavo Schiedeck ${ }^{\text {II }}$ José Ernani Schwengber ${ }^{\mathrm{II}}$ Ryan Noremberg Schubert ${ }^{\mathrm{II}}$ Caroline Voser Pereira $^{\mathrm{IV}}$
\end{abstract}

\section{- NOTA -}

\section{RESUMO}

O estudo foi realizado em uma propriedade agrícola familiar de base ecológica em Morro Redondo (RS), com intuito de analisar o conhecimento local sobre a fauna edáfica e as práticas de manejo do solo no sistema de produção de hortaliças. A família agricultora ressaltou a função das minhocas no solo, além de compreender que as práticas de manejo influenciam a fauna edáfica. A densidade da fauna edáfica foi maior no inverno, porém com diminuição da diversidade e aumento da dominância. O potencial do uso do conhecimento local como um importante aliado ao conhecimento acadêmico na avaliação da influência das práticas de manejo na fauna edáfica é discutido neste artigo.

Palavras-chave: etnoecologia, invertebrados do solo, Enchytraeidae, Oligochaeta.

\section{ABSTRACT}

The study was conducted on an agroecological family farm in Morro Redondo (RS) in order to verify local knowledge about soil fauna and management practices in ecological horticultural production systems. The family farmer emphasized the role of earthworms in the soil and recognized the influence of management practices on soil fauna. The soil fauna density was higher in winter time, but the diversity was reduced and the dominance was increased. The potential use of local knowledge as a valuable contribution to academic knowledge for assessing the influence of management practices on soil fauna is discussed in this paper.

Key words: ethnoecology, soil invertebrates, Enchytraeidae, Oligochaeta.

No cultivo de hortaliças, o solo é utilizado de forma intensiva, com uso de práticas como o arado e a enxada rotativa, que ocasionam desestruturação e compactação do solo, influenciando suas propriedades físicas, químicas e biológicas (SOUZA \& RESENDE, 2003). Essas práticas são utilizadas tanto no sistema de produção convencional como no de base ecológica.

Os efeitos das práticas de manejo nas propriedades biológicas do solo podem ser visualizados de forma mais rápida, principalmente através da análise de alguns grupos de invertebrados sensíveis as modificações no ambiente (LAVELLE et al., 2006). A associação entre o conhecimento acadêmico e o conhecimento localmente desenvolvido pelos agricultores é fundamental para a qualificação das práticas de manejo do solo (BARRIOS \& TREJO, 2003). Com isso, o objetivo do trabalho foi analisar o conhecimento local de uma família agricultora quanto à fauna edáfica e sua relação com as práticas de manejo, identificando os grupos taxonômicos dos organismos, suas relações com as propriedades químicas do solo, em um sistema de produção de base ecológica de hortaliças.

Para isso, conduziu-se o estudo em uma propriedade agrícola familiar de base ecológica localizada no distrito Rincão da Caneleira, Morro Redondo, Rio Grande do Sul (31 $\left.{ }^{\circ} 32^{`} \mathrm{~S} ; 52^{\circ} 37^{`} \mathrm{~W}\right)$. Para captar o conhecimento local da família agricultora foi realizada uma entrevista aberta, semiestruturada e em linguagem adequada, utilizando gravador digital, com todos os membros da família

'Escola Estadual de Ensino Médio Santa Rita, 96055-830, Pelotas, RS, Brasil.E-mail: greice_eco@hotmail.com. Autor para correspondência.

${ }^{\mathrm{II}}$ Universidade Federal de Pelotas (UFPel), Pelotas, RS, Brasil.

IIIEmbrapa Clima Temperado, Estação Experimental Cascata, Pelotas, RS, Brasil.

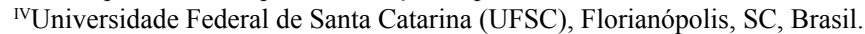


ao mesmo tempo (7 pessoas), utilizando os seguintes questionamentos: que organismos da fauna edáfica você conhece?; qual a função da fauna edáfica no solo?; as práticas de manejo influenciam na presença desta?; quais características do solo condicionam a vida neste local?

Além da entrevista, foram definidos sete canteiros de hortaliças para as avaliações biológicas (fauna edáfica) e químicas do solo $(\mathrm{pH}, \mathrm{Ca}, \mathrm{Mg}, \mathrm{Al}$, $\mathrm{K}, \mathrm{H}+\mathrm{Al}$, Na, CTC, MO, P, Sat. bases, Cu, Zn, Mn). As coletas da fauna edáfica ocorreram na primavera (2010) e no verão, outono e inverno (2011), com a metodologia TSBF, descrita por ANDERSON \& INGRAM (1993), sendo retirado um bloco de solo $(25 \times 25 \times 30 \mathrm{~cm})$ por canteiro. O solo foi triado manualmente, para a identificação dos grupos, Oligochaeta (Enchytraeidae e outras) [Annelida], Araneae, Isopoda, Blattodea, Isoptera, Diptera, Dermaptera, Orthoptera, Hemiptera, Coleoptera, Hymenoptera (Formicidae e outras), Diplopoda, Chilopoda [Arthropoda] e imaturos.

Os dados da fauna edáfica passaram pela análise dos índices ecológicos, como riqueza de espécies, frequência relativa dos grupos taxonômicos, dominância de Berger-Parker, diversidade de Shannon e equitabilidade de Shannon. As propriedades biológicas e químicas do solo foram submetidas à análise de componentes principais através do programa Statistica 7.0.

A família agricultora reconhece onze grupos taxonômicos como minhocas (Oligochaeta); ácaro (Acari); aranha (Araneae); tatu-bola (Isopoda); cachorrinho da terra (Orthoptera); pulgão e percevejo (Hemiptera); cascudo, joaninha e coró (Coleoptera); borboleta (Lepidoptera); formigas e abelhas (Hymenoptera) e caracol (Gastropoda). Além destes grupos citados pelos agricultores, com exceção de Lepidoptera e Gastropoda, foram também encontrados, através das coletas, os grupos Enchytraeidae, Blattodea, Isoptera, Diptera, Dermaptera, Diplopoda e Chilopoda.

Pôde-se observar que a densidade de indivíduos foi maior no inverno, diferindo significativamente da primavera e do verão. A riqueza permaneceu a mesma, não apresentando diferença significativa entre as estações. A diversidade da fauna edáfica foi maior na primavera e no verão, diminuindo significativamente no outono e no inverno. A dominância de alguns grupos foi maior no outono e inverno com diferença significativa da primavera e verão (Tabela 1). KLENK (2010) concluiu que em áreas de pastagens com preparo orgânico, a densidade da fauna edáfica foi maior no outono e no inverno, porém não encontrou diferença estatística significativa.

Neste trabalho três grupos destacaramse com maior frequência relativa em todas as estações, como os enquitreídeos (61\%), as formigas $(18 \%)$ e as minhocas (4\%). Esses grupos são considerados "engenheiros do ecossistema", pois atuam na modificação do ambiente físico e químico, influenciando a dinâmica do solo e o ecossistema (LAVELLE et al., 2006).

A família agricultora ressaltou a função das minhocas na decomposição da matéria orgânica e na aeração do solo, o que reflete nas propriedades do mesmo. Concorda-se com BROWN \& DOMÍNGUEZ (2010) que a população de minhocas pode ser um indicador de qualidade do solo, pois os agricultores reconheceram a sua importância nos processos e, assim como constatado por LIMA \& BRUSSAARD (2010), eles também evidenciaram sua fácil visualização no solo.

Salienta-se que as práticas de manejo influenciam a presença da fauna edáfica, principalmente aquelas que modificam a estrutura do solo. Algumas espécies de minhocas sofrem influência negativa a partir de práticas como o preparo do solo, compactação, queimadas (BROWN; DOMÍNGUEZ, 2010). De acordo com a família agricultora, o preparo do sistema pode afetar negativamente a qualidade do solo, pois é realizado com enxada rotativa. Porém, algumas práticas do sistema afetam positivamente as populações de minhocas, como adubação orgânica, manutenção de coberturas verdes e cobertura morta (BROWN \& DOMÍNGUEZ, 2010).

Tabela 1 - Parâmetros ecológicos da fauna edáfica coletada em sistema de produção de base ecológica, no município de Morro Redondo (RS), em diferentes estações (primavera, verão, outono e inverno), 2010/2011.

\begin{tabular}{|c|c|c|c|c|c|c|c|c|}
\hline \multirow[b]{2}{*}{ Densidade (ind $\mathrm{m}^{-2}$ ) } & \multicolumn{2}{|c|}{------ Primavera ------ } & \multicolumn{2}{|c|}{------- Verão --------- } & \multicolumn{2}{|c|}{----- Outono -------- } & \multicolumn{2}{|c|}{-------- Inverno -----. } \\
\hline & 590 & $\mathrm{C}$ & 922 & $\mathrm{BC}$ & 2151 & $\mathrm{AB}$ & 2528 & A \\
\hline Riqueza (S) & 7 & NS & 7 & NS & 5 & NS & 7 & NS \\
\hline Diversidade de Shannon $(\mathrm{H})$ & 0,59547 & A & 0,60766 & A & 0,31716 & $\mathrm{~B}$ & 0,2954 & $\mathrm{~B}$ \\
\hline Equitabilidade de Pielou (J) & 0,74104 & A & 0,7442 & A & 0,44389 & $\mathrm{~B}$ & 0,36161 & $\mathrm{~B}$ \\
\hline Dominância de Berger-Parker (Dbp) & 0,5099 & A & 0,46544 & $\mathrm{~A}$ & 0,75829 & $\mathrm{~B}$ & 0,82019 & $\mathrm{~B}$ \\
\hline
\end{tabular}

Letras diferentes, na mesma linha, indicam diferenças estatísticas pelo teste de Duncan a 5\% de probabilidade. NS: não significativo. 
As propriedades do solo que a família reconhece como condicionante para a fauna edáfica são a quantidade de matéria orgânica e a estrutura física do solo. Vale ressaltar que na área de estudo constatou-se baixos teores (na faixa de 2,5 \%) de matéria orgânica. No entanto, os agricultores ressaltam sua importância para a alimentação dos organismos e para o processo de decomposição. Com ênfase aos engenheiros do ecossistema, sabe-se que a fauna edáfica apresenta relação direta com a matéria orgânica, pela decomposição, proteção com estruturas biogênicas e distribuição no perfil do solo (LAVELLE et al.,2006).

Com a análise de componentes principais foi possível descrever $61,9 \%$ da variação total (Fator 1: 40,36\%; Fator 2: $21,62 \%$ ). As variáveis biológicas e químicas altamente correlacionadas entre si foram: Formicidae e Araneae; Chilopoda e capacidade de troca de cátions; Enchytraeidae e manganês. Formigas e aranhas podem ser consideradas sensíveis às práticas de manejo, sendo que a utilização de práticas inadequadas refletem na comunidade de aranhas (ANDERSEN et al., 2002), porém, nesta pesquisa, estes grupos apresentaram uma baixa densidade. A presença de formigas pode refletir na fase de recuperação do solo, com uma variabilidade de hábitos alimentares e vivendo em agregados com alta densidade (ANDERSEN et al., 2002).

Os enquitreídeos atuam nos processos de decomposição da matéria orgânica, na ciclagem de nutrientes e apresentam importância nas áreas com solos ácidos e pobres em nutrientes, principalmente em áreas de clima temperado, onde este grupo é, em geral, mais dominante (MARALDO, 2009). O resultado deste trabalho revela a correlação forte deste grupo com o Manganês (Mn), sendo que esse dado sugere que o Mn pode ser um fator determinante para a dominância de enquitreídeos na região.

A família enfatizou que nem todos os organismos citados, por eles, apresentam benefícios para o sistema de produção, pois as práticas de manejo podem causar um desequilíbrio aumentando a população de algum grupo. Segundo ALTIERI \& NICHOLLS (2010), alguns insetos que se tornam "pragas" demonstram a instabilidade dos sistemas. Com isso, é necessário repensar as práticas, mesmo aquelas adotadas nos sistemas de produção de base ecológica.

Contudo, ressalta-se o conhecimento da família agricultora de vários grupos taxonômicos da fauna edáfica, com ênfase ao papel das minhocas (Oligochaeta). Logo, o conhecimento local é um importante aliado ao conhecimento acadêmico, mas ainda é necessário aprofundar os conhecimentos referentes à fauna edáfica e suas relações, nos sistemas de produção de base ecológica de hortaliças.

\section{AGRADECIMENTOS}

Os autores agradecem à família agricultora e ao apoio financeiro do Conselho Nacional de Desenvolvimento Científico e Tecnológico (CNPq), Fundação de Amparo à Pesquisa e Inovação do Estado de Santa Catarina (FAPESC) e Fundação de Amparo à Pesquisa do Estado do Rio Grande do Sul (FAPERGS) através dos projetos: "Construção e qualificação da sustentabilidade de agroecossistemas em propriedades agrícolas familiares" (Processo $\left.\mathrm{n}^{\mathrm{o}} 562825 / 2010-0\right)$ e "Tecnologias para o desenvolvimento sustentável de sistemas de produção de hortaliças" (Processo 562444/2010-6), aprovados pelo edital do $n^{\circ} 22 / 2010$ - Redes Nacionais de Pesquisa em Agrobiodiversidade e Sustentabilidade Agropecuária (REPENSA).

\section{REFERÊNCIAS}

ALTIERI, M.A; NICHOLLS, I.C. Diseños agroecologicos: para incrementar la biodiversidad de entomofauna benefica em agroecosistemas. Colombia: Sociedade Científica Latinoamericana de Agroecologia (SOCLA), 2010. 83p.

ANDERSEN, A. et al. Using ants as bioindicators in land management: simplifying assessment of ant community responses. Journal of Applied Ecology, v.39, n.1, p.8-17, 2002. Disponível em: $<$ http://onlinelibrary.wiley.com/doi/10.1046/j.13652664.2002.00704.x/full $>$. Acesso em: 10 jun. 2011. doi: 10.1046/ j1365-2664.2002.00704.x.

ANDERSON, J.M.; INGRAM, J.S. Tropical Soil Biology and Fertility, a handbook of methods. 2.ed. Wallingford: Commonwealth Agricultural Bureau, 1993. 221p.

BARRIOS, E.; TREJO, M. T. Implications of local soil knowledge for integrated soil management in Latin America. Geoderma, v.111, n.3-4, p.217-231, 2003. Disponível: <http://ciat-library.ciat. cgiar.org/articulos_ciat/Barrios_Geoderma.pdf $>$. Acesso em: 15 out. 2010. doi: 10.1016/S0016-7061(02)00265-3.

BROWN, G.G.; DOMÍNGUEZ, J. Uso das minhocas como bioindicadoras ambientais: princípios e práticas - o $3^{\circ}$ Encontro Latino Americano de Ecologia e Taxonomia de Oligoquetas (ELAETAO 3). Acta Zoológica Mexicana (nueva serie), v.26, n.2, p.1-18, 2010. Disponível em: <http://www.redalyc.org/ pdf/575/57515556001.pdf $>$. Acesso em: 15 abr. 2010.

KLENK, L.A. Macrofauna invertebrada edáfica em pastagem com pastoreio rotativo sob diferentes preparos orgânicos em condições subtropicais no sul do Brasil. 2010. 54f. Dissertação (Mestrado em Ciência do Solo) - Ciências Agrárias, Universidade Federal do Paraná, PR.

LAVELLE, P. et al. Soil invertebrates and ecosystems services. European Journal of Soil Biology, v.42, n.1, p.3-15, 2006. Disponível em: <http:/www.sciencedirect.com/science/article/pii/ S1164556306001038>. Acesso em: 24 jul. 2010. doi: 10.1016/j. ejsobi.2006.10.002.

LIMA, A. C. R.; BRUSSAARD, L. Earthworms as soil quality indicators: local and scientific knowledge in rice management systems. Acta Zoológica Mexicana, v.26, n.2, p.109-116, 2010.

MARALDO, K. Enchytraeidae (Oligochaeta) in a changing climate: ecology and ecophysiology of enchytraeids exposed to climate changes. 2009. 131f. Tese (PhD in Terrestrial Ecology) Univesity of Copenhagen.

SOUZA, J.L.; RESENDE, P. Manual de Horticultura Orgânica. Viçosa: Aprenda Fácil, 2003. 564p.

Ciência Rural, v.45, n.4, abr, 2015. 